\title{
$\Delta 133 p 53 a$, a natural p53 isoform, contributes to conditional reprogramming and long-term proliferation of primary epithelial cells
}

\author{
Abdul M. Mondal ${ }^{1}$, Hua Zhou ${ }^{1,2}$, Izumi Horikawa ${ }^{3}$, Frank A. Suprynowicz ${ }^{1}$, Guangzhao Li', Aleksandra Dakic ${ }^{1}$, \\ Bernard Rosenthal', Lin Ye ${ }^{1,4}$, Curtis C. Harris ${ }^{3}$, Richard Schlegel ${ }^{1}$ and Xuefeng Liu (B) ${ }^{1,5,6}$
}

\begin{abstract}
We previously developed the technique of conditional reprogramming $(\mathrm{CR})$, which allows primary epithelial cells from fresh or cryopreserved specimens to be propagated long-term in vitro, while maintaining their genetic stability and differentiation potential. This method requires a combination of irradiated fibroblast feeder cells and a Rho-associated kinase (ROCK) inhibitor. In the present study, we demonstrate increased levels of full-length p53 and its natural isoform, $\triangle 133 p 53 a$, in conditionally reprogrammed epithelial cells from primary prostate, foreskin, ectocervical, and mammary tissues. Increased $\triangle 133 p 53$ a expression is critical for $C R$ since cell proliferation is rapidly inhibited following siRNA knockdown of endogenous $\triangle 133 p 53 a$. Importantly, overexpression of $\triangle 133 p 53 a$ consistently delays the onset of cellular senescence of primary cells when cultured under non-CR conditions in normal keratinocyte growth medium (KGM). More significantly, the combination of $\triangle 133 p 53 a$ overexpression and ROCK inhibitor, without feeder cells, enables primary epithelial cells to be propagated long-term in vitro. We also show that $\triangle 133 p 53 a$ overexpression induces hTERT expression and telomerase activity and that siRNA knockdown of hTERT causes rapid inhibition of cell proliferation, indicating a critical role of hTERT for mediating the effects of $\triangle 133 \mathrm{p} 53 \mathrm{a}$. Altogether, these data demonstrate a functional and regulatory link between p53 pathways and hTERT expression during the conditional reprogramming of primary epithelial cells.
\end{abstract}

\section{Introduction}

Primary human epithelial cells have a limited replicative lifespan in culture and their proliferation decreases rather rapidly (typically < 11 passages), leading to cellular senescence $^{1-3}$. For decades, scientists have sought to develop methods for propagating normal and tumor primary cells efficiently and indefinitely for research in cancer biology and therapeutics ${ }^{4,5}$. Established methods

\footnotetext{
Correspondence: Richard Schlegel (richard.schlegel@georgetwon.edu) or Xuefeng Liu (xuefeng.liu@georgetown.edu)

${ }^{1}$ Center for Cell Reprograming, Department of Pathology, Georgetown University Medical Center, Georgrtown, WA 20057, USA

${ }^{2}$ Guizhou Medical University, Guiyang, Guizhou, China

Full list of author information is available at the end of the article.

Edited by I. Amelio
}

for cellular immortalization involve the introduction of exogenous viral and/or cellular oncogene(s), such that these cell lines do not reflect a normal genotype ${ }^{6-10}$. Recently we established the technology of conditional reprogramming $(\mathrm{CR})$, that enables normal and tumor primary epithelial cells to be propagated indefinitely in vitro while maintaining their original karyotype ${ }^{11,12}$. This methodology has opened up a new platform for basic and clinical research, with potential applications for regenerative and personalized medicine ${ }^{13-15}$.

The p53 tumor suppressor protein is a sequence-specific transcription factor that regulates cellular proliferation and apoptosis through the repression or activation of downstream target genes ${ }^{16,17}$. The absence of functional p53

\section{(c) The Author(s) 2018}

(c) (i) Open Access This article is licensed under a Creative Commons Attribution 4.0 International License, which permits use, sharing, adaptation, distribution and reproduction in any medium or format, as long as you give appropriate credit to the original author(s) and the source, provide a link to the Creative Commons license, and indicate if changes were made. The images or other third party material in this article are included in the article's Creative Commons license, unless indicated otherwise in a credit line to the material. If material is not included in the article's Creative Commons license and your intended use is not permitted by statutory regulation or exceeds the permitted use, you will need to obtain permission directly from the copyright holder. To view a copy of this license, visit http://creativecommons.org/licenses/by/4.0/. 
leads to neoplastic transformation ${ }^{18}$. To date, 14 natural

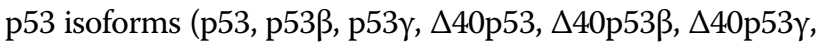
$\Delta 133 p 53, \Delta 133 p 53 \beta, \Delta 133 p 53 \gamma, \Delta 160 p 53, \Delta 160 p 53 \beta$, $\Delta 160 \mathrm{p} 53 \gamma, \Delta \mathrm{p} 53$, and $\mathrm{p} 53 \psi$ ) have been identified and many of them elicit distinct biological phenotypes ${ }^{19-24}$. While the functions of wild-type full-length p53 are well defined, the physiological role of various p53 isoforms in senescence, growth arrest and apoptosis are connected in a complex and often apparently conflicting manner. Previously, we showed that two p53 isoforms, $\Delta 133 \mathrm{p} 53 \alpha$ and $\mathrm{p} 53 \beta$, potentially regulate cellular proliferation in human fibroblasts (MRC-5 and WI-38), lymphoid cells $\left(\mathrm{CD}^{+}{ }^{+} \mathrm{T}\right.$ lymphocytes) and astrocytes in vitro and in vivo ${ }^{25-27}$.

In the present study, we demonstrate that $\Delta 133 \mathrm{p} 53 \alpha$ regulates proliferation in conditionally reprogrammed epithelial cells isolated from prostates and foreskin tissues. Overexpression of $\Delta 133 \mathrm{p} 53 \alpha$ consistently delays cellular senescence and enables primary cells to be propagated in vitro indefinitely in the presence of a Rhoassociated kinase (ROCK) inhibitor. The mechanism underlying $\Delta 133 \mathrm{p} 53 \alpha$-extended replicative lifespan involves the upregulation of hTERT expression and its telomerase activity.

\section{Materials and methods}

\section{Cell cultures and reagents}

Neonatal foreskins (foreskin-1, foreskin-2), normal adult prostate tissues (prostate-1 and prostate-2), ectocervical and mammary tissues were collected from patients in accordance with Georgetown University Institutional Review Board (IRB) protocols ${ }^{12,28,29}$. Primary cells were isolated as described previously ${ }^{11}$. Briefly, samples were minced and digested with a mixture of dispase (Fisher Scientific) and collagenase (STEMCELL Technologies) and filtered through a $100-\mu \mathrm{m}$ strainer to remove connective tissue. The isolated human foreskin keratinocytes (HFKs) and human prostate epithelial cells (HPECs) were cultured either in KGM [Keratinocyte-SFM supplemented with recombinant epidermal growth factor 1-53 (EGF 1-53) and bovine pituitary extract] (Gibco), or in CRC: F medium [3:1 (v/v) DMEM (Dulbecco's Modified Eagle Medium) (containing 10\% (v/v) fetal bovine serum): F-12 nutrient mix] containing $0.125 \mathrm{ng} / \mathrm{ml}$ epidermal growth factor, $25 \mathrm{ng} / \mathrm{ml}$ hydrocortisone, $5 \mu \mathrm{g} / \mathrm{ml}$ insulin, $0.1 \mathrm{nM}$ cholera toxin (Sigma-Aldrich), $10 \mu \mathrm{g} / \mathrm{ml}$ gentamicin, $250 \mathrm{ng} / \mathrm{ml}$ amphotericin B (Gibco) and $10 \mu \mathrm{M}$ Y-27632 (Enzo Life Sciences) ${ }^{11}$ in the presence of irradiated Swiss 3T3-J2 fibroblasts. Where indicated, cells also were cultured in KGM containing $10 \mu \mathrm{M}$ Y-27632 or in conditioned medium (CM) containing $10 \mu \mathrm{M}$ Y-27632. CM was prepared from irradiated Swiss 3T3-J2 fibroblasts as described previously ${ }^{11}$. All cultures were maintained in a humidified incubator with $5 \% \mathrm{CO}_{2}$ at $37^{\circ} \mathrm{C}$ and passaged 1:4 (cultures without irradiated fibroblasts) or 1:8 (cultures with irradiated fibroblasts) when $80-90 \%$ confluent. Cell viability was determined by trypan blue exclusion before every passage. In addition to primary cells derived from tissue, MRC-5, WI-38, U2OS, HT1080, and 293T cell lines were from American Type Culture Collection. Population doublings were calculated as $\log _{10}$ (final number of cells) $-\log _{10}$ (initial number of cells)/ $\log _{10} 2^{25}$. To quantify short-term proliferation ( $<8$ days), cultures were monitored using the IncuCyte live-cell analysis system with IncuCyte ZOOM software (Essen BioScience).

\section{Separation of epithelial cells from irradiated fibroblasts}

A two-step trypsin protocol was used to harvest epithelial cells from co-cultures with irradiated J2 fibroblasts $^{12}$. Briefly, cultures were rinsed with Phosphate Buffered Saline (PBS) and incubated with 0.05\% trypsin for 30-60 s at room temperature. J2 cells were removed by gentle tapping and aspiration. The epithelial cells were then rinsed with PBS, treated with trypsin for 3-5 min at $37^{\circ} \mathrm{C}$ and detached from the flask by gentle tapping. Stop buffer (10\% FBS in PBS) was added to neutralize the trypsin and the cell suspension was centrifuged for $5 \mathrm{~min}$ at $500 \times g$. Cell pellets were resuspended in medium for passaging or were washed with PBS at $4{ }^{\circ} \mathrm{C}$ and solubilized for analysis.

\section{Immunoblot analysis}

Total cell lysates were prepared as previously described $^{25,26}$. Briefly, cells were lysed in 1x RIPA buffer (Cell Signaling) containing a protease inhibitor cocktail (SigmaAldrich) and 0.1\% SDS. Following sodium dodecyl sulfate polyacrylamide gel electrophoresis (Novex Tris-Glycine Gels, Invitrogen), samples were transferred to Polyvinylidene Fluoride (PVDF) membranes (Bio-Rad) and incubated with primary and secondary antibodies as listed below. Chemiluminescence was detected using western blotting Luminol Reagent (Santa Cruz Biotechnology) or SuperSignal West Dura Substrate (Pierce Biotechnology). Quantitative analysis of immunoblots was performed using ImageJ 1.40 software (http://rsb.info.nih.gov/ij/).

\section{Antibodies}

The primary antibodies used were: DO-1 (1:1000; mouse monoclonal, Santa Cruz Biotechnology) for fulllength p53; MAP4 (1:7500; rabbit polyclonal raised against a mixture of peptides MFCQLAKTC and FCQLAKTCP corresponding to the amino-terminus of human $\Delta 133 \mathrm{p} 53 \alpha$, refs. ${ }^{25,26,30}$ ) for $\Delta 133 \mathrm{p} 53 \alpha$; TLQi9 (1:5000; rabbit polyclonal raised against the peptide TLQDQTSFQKENC corresponding to the carboxylterminus of human $\mathrm{p} 53 \beta$, TLQ40 or KJC8, refs. ${ }^{20,25}$ ) for p53 $\beta$, CM1 (1:1000; rabbit polyclonal, ref. $\left.{ }^{24-26}\right)$ and GAPDH (0411) (1:1000; mouse monoclonal, Santa Cruz 
Biotechnology) for GAPDH. Secondary antibodies (horseradish peroxidase-conjugated goat anti-mouse IgG and goat anti-rabbit IgG) were obtained from Santa Cruz Biotechnology and used at a dilution of 1:5000.

\section{Preparation of lentiviral particles and transduction}

$\Delta 133 p 53 \alpha$ complementary DNA (cDNA) ${ }^{25}$ was cloned into the lentiviral vector pLoc-GFP-blasticidin (Open Biosystem). Lentiviral constructs, together with the Trans-Lentiviral GIPZ packaging system (Open Biosystem), were transfected into 293T/17 cells using Lipofectamine-2000 (Invitrogen). Viral particles were collected $48 \mathrm{~h}$ later and stored as aliquots at $-80^{\circ} \mathrm{C}$. Vector control lentiviral particles (pLoc-RFP-GFP) were similarly prepared. Viral particles were titrated in HT1080 cells and showed $>10^{6} \mathrm{TU} / \mathrm{ml}$. For transduction of epithelial cells, $50 \%$ confluent cultures were incubated with lentiviral particles for $6 \mathrm{~h}$ in the presence of $5 \mu \mathrm{g} / \mathrm{ml}$ polybrene (Santa Cruz Biotechnology). Subsequently, the polybrene-containing medium was replaced with fresh culture medium. After 2 days, the cells were re-plated at a dilution of 1:3-1:5, depending on the cell type and density. Two days later, cultures were selected for 10-12 days using $4-8 \mu \mathrm{g} / \mathrm{ml}$ blasticidin (Invitrogen).

\section{Quantitative reverse transcription PCR (qRT-PCR)}

RNA was isolated from cell cultures using the RNeasy Plus Mini Kit (Qiagen). cDNA was generated using the SuperScript III First-Strand Synthesis System (Invitrogen). iQ SYBR Green Supermix (Bio-Rad \#1708880) or SsoAdvanced Universal SYBR Green Supermix (Bio-Rad \#1725270) was used for $\Delta 133 \mathrm{p} 53 \alpha$ qRT-PCR (forward primer 5'-ACT CTG TCT CCT TCC TCT TCC TAC AG-3'; reverse primer 5'-TGA GGA GGG GCC AGA CCA $\left.\mathrm{TC}-3^{\prime}\right)^{25}$, for full-length p53 (forward primer $5^{\prime}$ CTT CCC TGG ATT GGC AGC CA-3'; reverse primer 5'-CAT TCT GGG AGC TTC ATC TGG AC-3'), for p21 (forward primer $5^{\prime}$-ATG TCA GAA CCG GCT GGG GA3'; reverse primer 5'-GCC GTT TTC GAC CCT GAG AG-3'), for E2F1 (forward primer 5'-TGC TCG ACT CCT CGC AGA TC-3'; reverse primer 5'-AGG AAG CGC TTG GTG GTC AG-3'), for PUMA (forward primer 5'-GAC TCC TGC CCT TAC CCA G-3'; reverse primer 5'-ATG GTG CAG AGA AAG TCC C-3'), for BAX (forward primer 5'-AAG AAG CTG AGC GAG TGT-3'; reverse primer $5^{\prime}$-GGA GGA AGT CCA ATG TC-3') and for NOXA (forward primer 5'-CGG AGA TGC CTG GGA AGA AG-3'; reverse primer 5'-AGG AGT CCC CTC ATG CAA GT-3'). The internal control was $\beta 2$ microglobulin (forward primer 5'-GGA CTG GTC TTT CTA TCT CTT GT-3'; reverse primer 5'-ACC TCC ATG ATG CTG CTT AC-3'). iQ Supermix (Bio-Rad \#1708862) was used for Taqman qRT-PCR to quantify hTERT mRNA expression using the following primers and probe: forward primer 5'-TGA CAC CTC ACC TCA CCC AC-3'; reverse primer 5'-CAC TGT CTT CCG CAA GTT CAC-3'; probe 5'-ACC CTG GTC CGA GGT GTC CC$3^{\prime}$. Normalized RNA expression was calculated using the $\Delta \Delta \mathrm{Ct}$ method according to the supplier's protocol (BioRad CFX Manager software).

\section{Small interfering RNA (siRNA) knockdown}

A stealth siRNA duplex oligoribonucleotide targeting $\Delta 133 p 53 \alpha$ mRNA ( $\Delta 133$-si 1 ; 5 '-UGU UCA CUU GUG CCC UGA CUU UCA A-3'), its scrambled control and a standard siRNA duplex oligoribonucleotide targeting $\Delta 133$ p53 $\alpha$ mRNA $\left(\Delta 133\right.$-si\#2; $5^{\prime}$-CUU GUG CCC UGA CUU UCA A[dT] $[\mathrm{dT}]-3^{\prime}$ ) were purchased from Invitrogen. Both $\Delta 133$-si $\# 1$ and $\Delta 133$-si $\# 2$ were designed to target regions that are present in $\Delta 133 \mathrm{p} 53 \alpha \mathrm{mRNA}$ as a $5^{\prime}$-UTR but spliced out of full-length p $53 \alpha$ mRNA as intron $4^{25}$. For hTERT knockdown, the following siRNAs were purchased from Dharmacon: siGENOME hTERT SMARTpool (5'-GGU AUG CCG UGG UCC AGA A-3', 5'-CCA CGU CUC UAC CUU GAC A-3', 5'-UCA CGG AGA CCA CGU UUC A- $3^{\prime}$ and $5^{\prime}$-GCG UGG UGA ACU UGC GGA A-3') and siGENOME non-targeting siRNA (5'-UAG CGA CUA AAC ACA UCA A-3'). HFKs and HPECs were transfected with siRNAs at a final concentration of $12 \mathrm{nM}$ for $\Delta 133 \mathrm{p} 53 \alpha$ knockdown and $25 \mathrm{nM}$ for hTERT knockdown using Lipofectamine RNAiMAX or Lipofectamine 3000 transfection reagents (Invitrogen) according to the manufacturer's protocols.

\section{Real-time quantitative TRAP assay for telomerase activity}

HFKs and HPECs transduced with $\triangle 133 \mathrm{p} 53 \alpha$ or vector control were grown to $80 \%$ confluence in $25 \mathrm{~mm}^{2}$ flasks, harvested by trypsin treatment, washed in cold PBS, and transferred to micro-centrifuge tubes. Cell pellets were lysed for $30 \mathrm{~min}$ at $4{ }^{\circ} \mathrm{C}$ in $200 \mu \mathrm{l}$ of TRAP buffer $(0.5 \%$ Chaps, $10 \mathrm{mM}$ Tris- $\mathrm{HCl} \mathrm{pH} 7.5,1 \mathrm{mM} \mathrm{MgCl}_{2}, 1 \mathrm{mM}$ EGTA, $5 \mathrm{mM} \beta$-mercaptoethanol, $10 \%$ glycerol and 0.1 $\mathrm{mM}$ 4-(2-aminoethyl)-benzenesulfonyl fluoride hydrochloride). Lysates were centrifuged at $14,000 \times g$ for $5 \mathrm{~min}$ at $4{ }^{\circ} \mathrm{C}$, supernatants were transferred to new tubes, and protein concentrations were determined using the Pierce $660 \mathrm{~nm}$ Protein Assay Reagent (Thermo Fisher). A quantitative TRAP assay was performed as described ${ }^{31-34}$, with some modifications. Briefly, $1.0 \mu \mathrm{g}$ of lysate protein was incubated for $60 \mathrm{~min}$ at $33^{\circ} \mathrm{C}$ in a $40 \mu$ reaction volume containing $1 \mathrm{x}$ PCR buffer $(20 \mathrm{mM}$ Tris- $\mathrm{HCl} \mathrm{pH}$ 8.4, $50 \mathrm{mM} \mathrm{KCl}), 1.5 \mathrm{mM} \mathrm{MgCl}_{2}, 0.5 \mu \mathrm{M}$ telomerase substrate primer $\left(5^{\prime}\right.$-AAT CCG TCG AGC AGA GTT$3^{\prime}$ ), $125 \mu \mathrm{M}$ of each deoxynucleotide triphosphate (dATP, dTTP, dGTP, and dCTP) and $0.5 \mu \mathrm{g}$ of T4 gene protein (Roche Applied Science). Telomerase was inactivated by heating at $95{ }^{\circ} \mathrm{C}$ for $10 \mathrm{~min}$. In the second step of the assay, SYBR Green qRT-PCR was performed to quantitate 


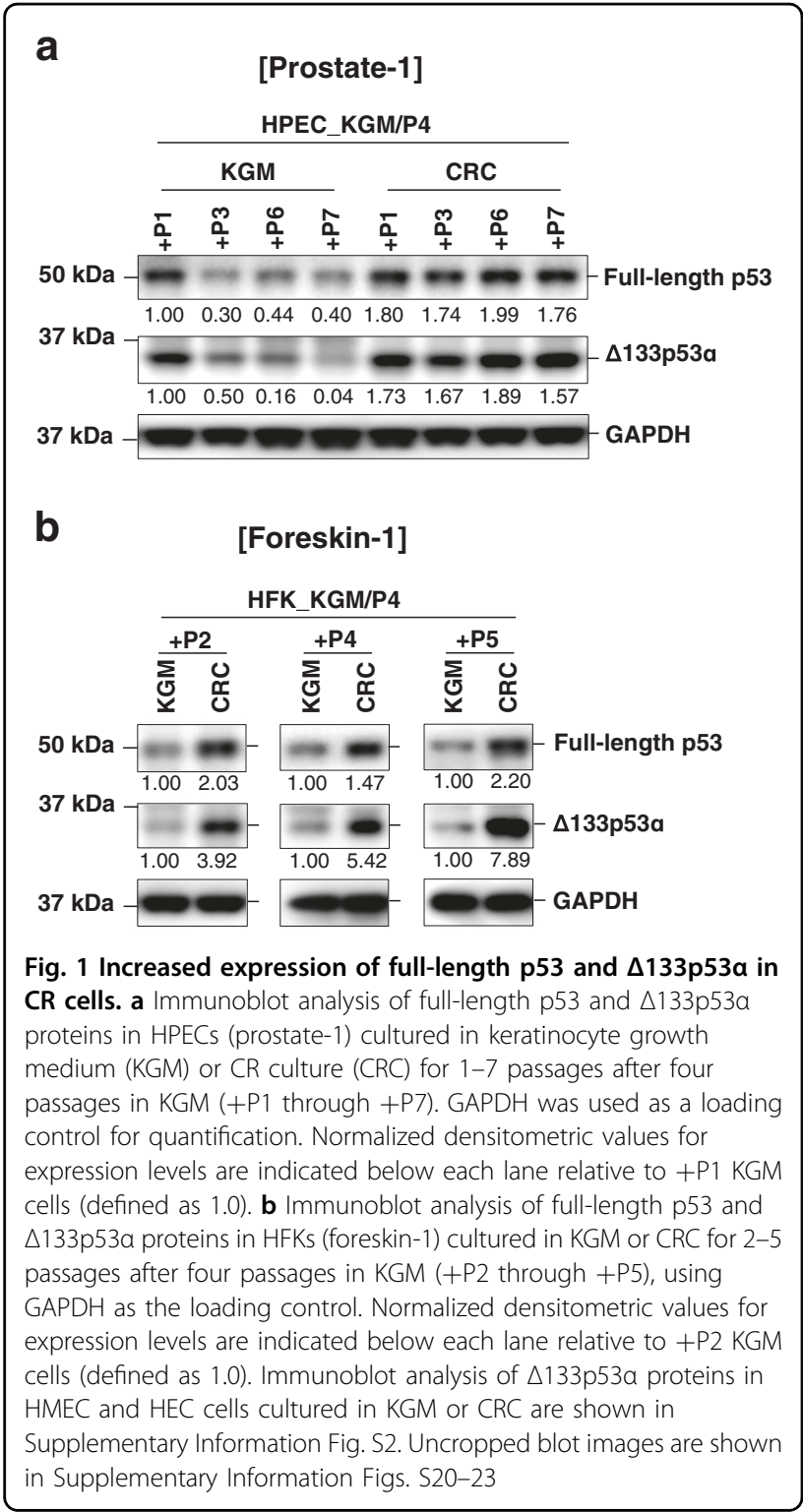

the number of substrate molecules to which telomere repeats had been added. Each $25-\mu l$ reaction contained $300 \mathrm{nM}$ of the above telomerase substrate primer and ACX primer (5'-GCG CGG CTT ACC CTT ACC CTT ACC CTA ACC-3'), and $1.0 \mu \mathrm{l}$ of product from the first step of the assay. A standard curve was generated for the quantitative TRAP assay using serially diluted HEK 293T cell extracts. All samples were assayed in triplicate. This assay is linear over at least a 500-fold range $(0.008-4 \mu \mathrm{g}$ of HEK 293T protein input).

\section{Senescence-associated $\beta$-galactosidase (SA- $\beta$-gal) assay}

KGM cells of HFKs at passage 4 (early passage) or passage 10 (late passage), CRC cells of HPECs after three passages in CRC or in CRC without feeders, and control or $\Delta 133 \mathrm{p} 53 \alpha$-overexpressing HFK cells at passage 6 in KGM were examined using Senescence $\beta$-Galactosidase Staining Kit (Cell Signaling) per the manufacturer's instructions.

\section{Statistics}

Statistical analyses were carried out using a two-tailed Student's $t$-test for paired and unpaired samples as appropriate. A $P$-value $<0.05$ was considered significant.

\section{Results}

CR cells exhibit increased expression of full-length p53 and $\Delta 133 p 53 a$

Since full-length $\mathrm{p} 53$ and $\Delta 133 \mathrm{p} 53 \alpha$ play important roles in the regulation of cellular senescence ${ }^{25,26,35}$ in several non-epithelial cell types, we measured their expression in primary HPECs grown in two culture conditions: (i) traditional keratinocyte growth medium (KGM), which does not support long-term cell proliferation, and (ii) conditional reprogramming culture (CRC), which mediates the long-term growth of many epithelial and non-epithelial cell types ${ }^{11,12}$. Both fulllength $\mathrm{p} 53$ and $\Delta 133 \mathrm{p} 53 \alpha$ were consistently at higher levels in the prostate CRC cells compared to the cells cultured in KGM (Fig. 1a and Supplementary Information Fig. S1a). Increased levels of full-length p53 and $\Delta 133 p 53 \alpha$ were also observed in CRC cells of primary HFKs (Fig. 1b and Supplementary Information Fig. S1b). In addition, the increased levels of $\Delta 133 \mathrm{p} 53 \alpha$ protein isoform in the CRC cells were consistent in other cell types, primary human ectocervical cells (HECs) and human mammary epithelial cells (HMECs) (Supplementary Information Fig. S2). We examined another p53 isoform, $\mathrm{p} 53 \beta$, which plays role in $\mathrm{p} 53$-mediated senescence and apoptosis ${ }^{20}$, was undetectable in these cell types; even at late passage in KGM where cells stopped dividing (Supplementary Information Fig. S3). Therefore, $\mathrm{p} 53 \beta$ isoform was ruled out as a significant regulator of CR in this study.

\section{Increased $\Delta 133 p 53 a$ expression correlates with $C R$ rescue of late-passage KGM cultures}

As shown previously ${ }^{11,12}$, normal human epithelial cells have a limited replicative lifespan in standard KGM culture, but can be propagated indefinitely in CR culture (Fig. 2a, b). However, late-passage KGM cells regain the capacity to proliferate if the culture conditions switched to CRC (Supplementary Information Fig. S4). Renewed proliferation was found to correlate with increased $\Delta 133 p 53 \alpha$ expression when passage 8 KGM cells of HFK (close to senescence; see Supplementary Information Fig. S5) were placed in CR culture for 1 or 2 passages (Fig. 2c, d). However, though there was initial increase of full-length p53, the rescued CRC cells showed lower levels 
a

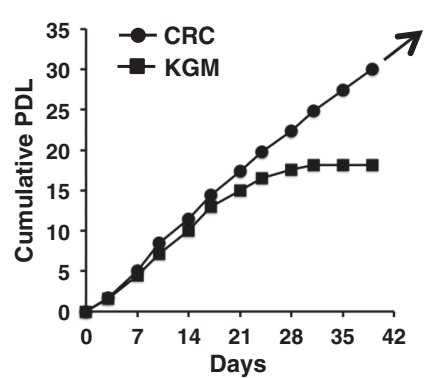

SWITCHING FROM KGM

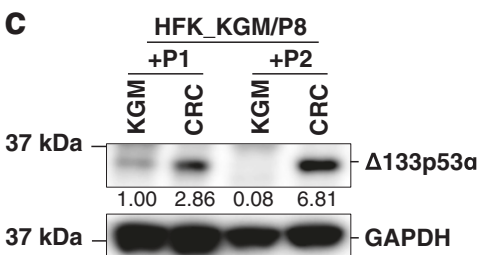

b
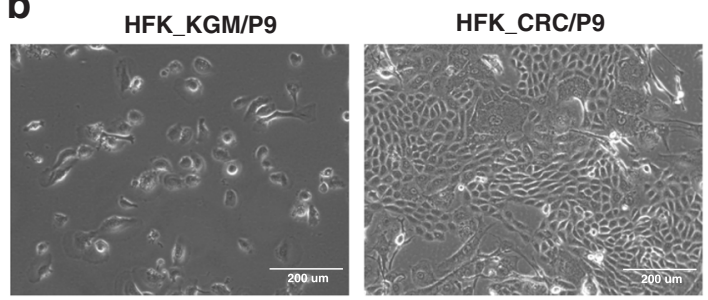

d $\quad \Delta 133 p 53 a$

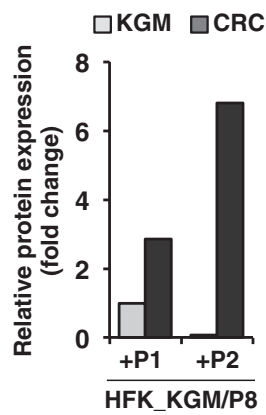

e

\section{SWITCHING FROM CRC}

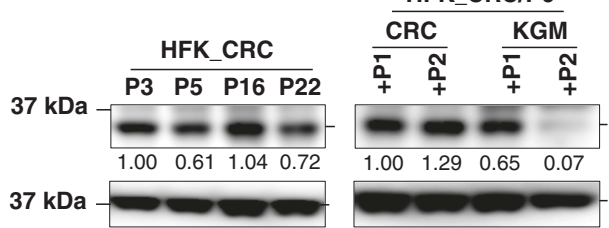

HFK_CRC/P22

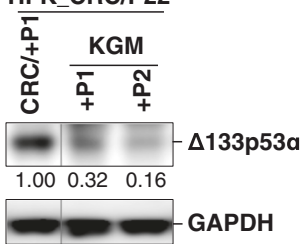

f

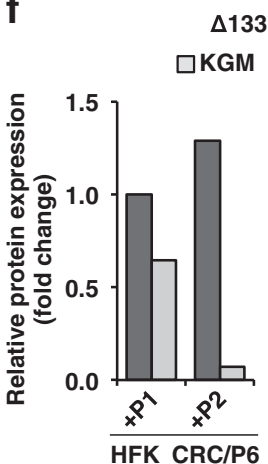

$\Delta 133 p 53 a$ $\square \mathrm{KGM} \quad \square \mathrm{CRC}$

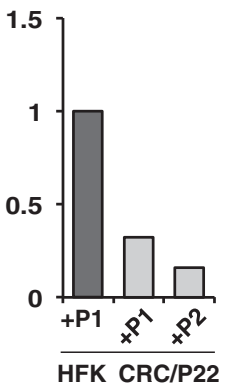

g

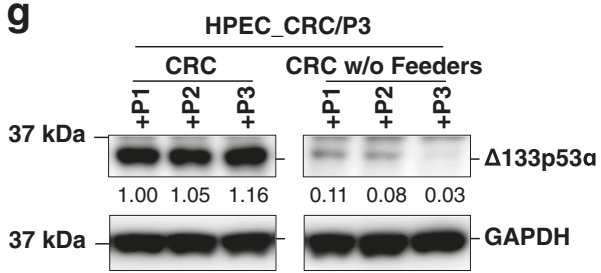

h $\Delta 133 p 53 a$

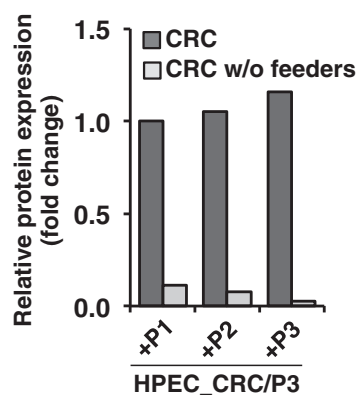

Fig. 2 (See legend on next page.) 


\begin{abstract}
(see figure on previous page)
Fig. 2 Increased $\Delta$ 133p53a expression correlates with cell proliferation. a Freshly isolated HFKs were cultured in KGM or CRC until the KGM cells stopped proliferating. Cumulative population doubling levels (PDL) were plotted vs. time (days). b Representative images of the HFKs at passage 9 in KGM or CRC. Scale bars: $200 \mu \mathrm{m}$. c Late-passage HFKs (P8) cultured in KGM were shifted to CRC (or maintained in KGM) for an additional two passages $(+\mathrm{P} 1$ and $+\mathrm{P} 2)$. The expression of $\triangle 133 \mathrm{p} 53 \mathrm{a}$ in these cultures was determined by immunoblot analysis. GAPDH was the loading control. Normalized densitometric values are indicated below each lane. $\mathbf{d}$ Bar graph of $\triangle 133 p 53$ a expression in the cultures shown in c. e HFKs cultured in CRC for 6 or 22 passages were transferred to KGM (or maintained in CRC) for an additional two passages (+P1 and +P2). Immunoblot analysis was used to quantify $\triangle 133$ p53a expression. $\triangle 133 p 53$ a levels were consistently high in CRC (P3 through P22), however, expression dramatically decreased when the cells were switched to KGM. GAPDH was the loading control. Normalized densitometric values are indicated below each lane. $\mathbf{f}$ Bar graph of $\triangle 133 p 53$ a expression in the middle and right panels shown in e. $\mathbf{g} \triangle 133 p 53$ a levels in HPECs initially cultured in CRC for three passages (HPEC_CRC/ P3) before transferring to CRC with or without irradiated feeder cells for an additional three passages (+P1, +P2, and +P3). GAPDH was the loading control. Normalized densitometric values are indicated below each lane. $\mathbf{h}$ Bar graph of the data shown in $\mathbf{g}$. Uncropped blot images are shown in Supplementary Information Figs. S26-28
\end{abstract}

of full-length p53 compared to their KGM counterparts (Supplementary Information Fig. S6). The increased p53 levels associated with enhanced proliferation in CR were not consistent when rescued at the later stage of their replicative lifespan. On the other hand, we observed consistent and abundant levels of $\Delta 133 \mathrm{p} 53 \alpha$ in the immediately rescued CRC cells and that prompted us to pursue investigating mainly the role of $\Delta 133 \mathrm{p} 53 \alpha$ isoform in CR. $\Delta 133$ p53 $\alpha$ expression in CR HFKs remained at a high level for at least 22 passages, but decreased rapidly (1-2 passages) and dramatically (up to 15-fold) when transitioned to KGM culture (Fig. 2e, f). The decrease in $\Delta 133 p 53 \alpha$ expression coincided with a rapid (1-2 passages) cessation of proliferation (Supplementary Information Fig. S7a, b). The correlation between proliferation and $\Delta 133 \mathrm{p} 53 \alpha$ levels was further demonstrated by removing irradiated mouse 3T3-J2 feeder cells from CR culture of HPECs. Following removal of the feeders, the HPECs stopped proliferating and became senescent within three passages (Supplementary Information Fig. S8a, b). The decrease in proliferative capacity coincided with decreased $\Delta 133 \mathrm{p} 53 \alpha$ expression (Fig. $2 \mathrm{~g}$, h). Altogether, these results show that $\Delta 133 \mathrm{p} 53 \alpha$ expression correlates with the proliferative capacity of primary epithelial cells in vitro, which is dependent upon feeder cells.

\section{Knockdown of endogenous $\Delta 133 p 53$ inhibits cell proliferation}

To investigate the importance of $\Delta 133 \mathrm{p} 53 \alpha$ for the proliferation of CR cells, we first transfected early-passage (P3-4) HFKs and HPECs in KGM culture with two siRNAs $(\Delta 133 p 53 \alpha$-siR\# 1 and $\Delta 133 p 53 \alpha$-siR\#2) previously used to knockdown $\Delta 133 \mathrm{p} 53 \alpha$ mRNA in human fibroblasts and lymphocytes ${ }^{25,26}$. As shown (Fig. 3a), $\Delta 133$ p $53 \alpha$-siR\# 1 reduced $\Delta 133$ p $53 \alpha$ protein levels by $60 \%$ and $\Delta 133 p 53 \alpha$-siR\# 2 by $40 \%$, without affecting full-length p53 levels. We then continuously monitored the proliferation of both knockdown and control cells (transfected with scrambled sequence siRNA) in KGM using
IncuCyte technology (see Methods) for 4 days after transfection. HFKs and HPECs transfected with $\Delta 133$ p $53 \alpha$-siRNAs underwent immediate growth arrest, whereas cells transfected with the control siRNA continued to proliferate at the same rate as non-transfected cells (Fig. 3b, c and Supplementary Information Fig. S9a, b). We next investigated the importance of $\Delta 133 p 53 \alpha$ for the proliferation of CRC cells by similarly knocking down endogenous $\Delta 133 \mathrm{p} 53 \alpha$ expression in the conditionally reprogrammed HFKs (Fig. 3d, f). The inhibition of cell proliferation was accompanied by loss of endogenous $\Delta 133 p 53 \alpha$ protein in the CR cells (Fig. 3d, e and Supplementary Information Fig. S10). As the conditionally reprogrammed cells showed increased basal levels of $\Delta 133 p 53 \alpha$, the siRNA-knockdown effects for growth inhibition took a little longer and were less efficient compared to the KGM cells where basal levels of $\Delta 133 p 53 \alpha$ were relatively low (Fig. 3c, e). However, the siRNAs used to target the $\triangle 133 \mathrm{p} 53 \mathrm{mRNA}$ also knockdown another $\mathrm{p} 53$ protein isoform $\Delta 160 \mathrm{p} 53 \alpha$ at the same time $^{24}$. Therefore, we further investigated the $\Delta 133 \mathrm{p} 53$ mRNA knockdown cells using CM1 antibody that reacts with both the $\Delta 133 \mathrm{p} 53 \alpha$ and $\Delta 160 \mathrm{p} 53 \alpha$ protein isoforms $^{24}$. None of the control or $\Delta 133 \mathrm{p} 53$ siRNA transfected cells showed any detectable $\Delta 160 \mathrm{p} 53 \alpha$ protein expression (Supplementary Information Fig. S11). Interestingly, we also noticed that knockdown of $\Delta 133 \mathrm{p} 53 \alpha$ isoform was associated with the loss of hTERT mRNA expression without affecting full-length p53 expression (Fig. 3f). These results suggest that $\Delta 133 \mathrm{p} 53 \alpha$ expression is necessary for the increased proliferation of CR epithelial cells and perhaps by upregulating hTERT expression.

\section{Overexpression of $\Delta 133 p 53 a$ extends the replicative lifespan of primary epithelial cells in KGM}

Since primary epithelial cells undergo senescence after 10-11 passages in KGM culture (Fig. 2a, b) with loss of endogenous $\Delta 133 \mathrm{p} 53 \alpha$ levels (Figs. 1a and 2c), we overexpressed $\Delta 133 \mathrm{p} 53 \alpha$ in HPECs and HFKs at relatively 


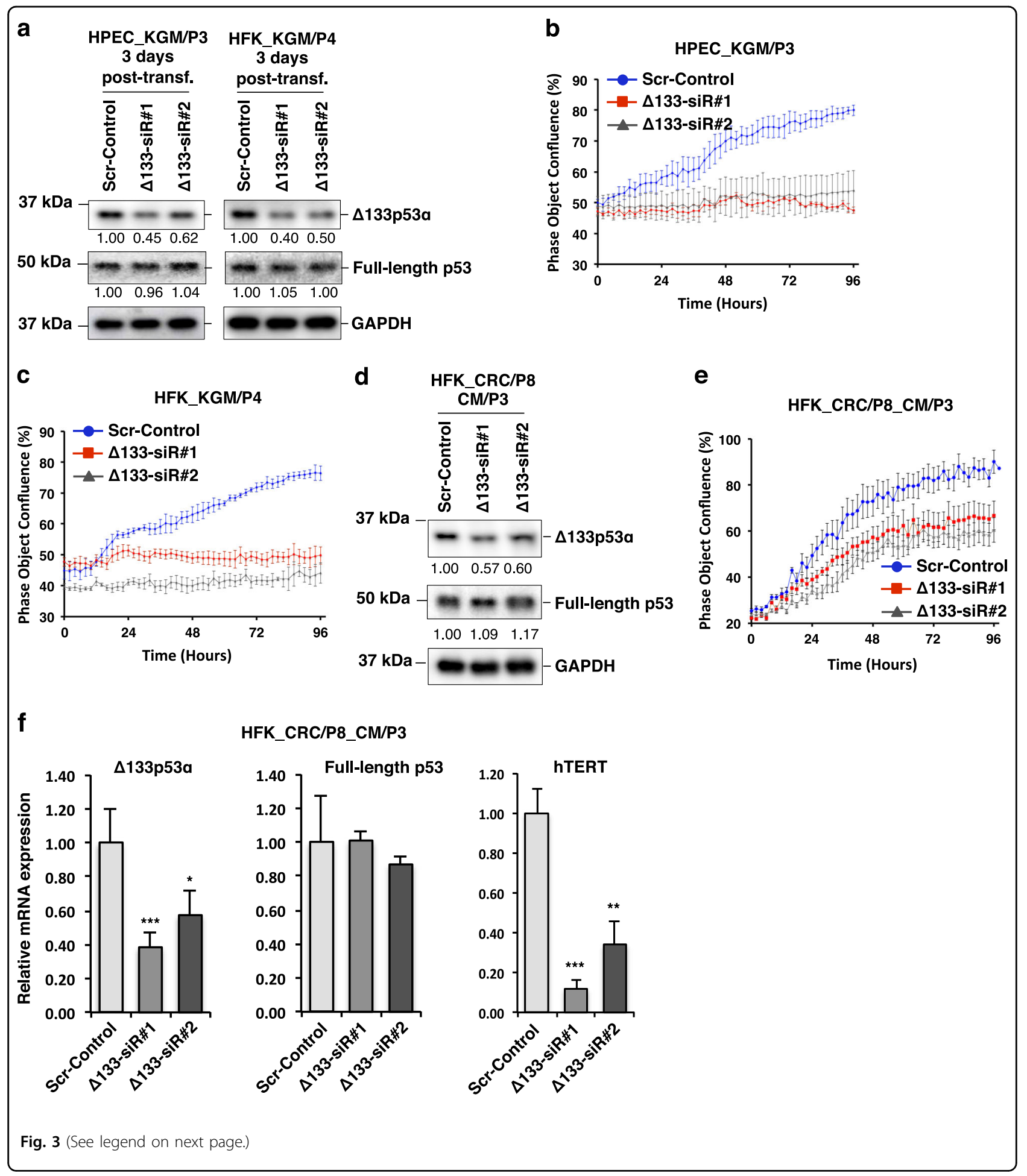

late-passage (P6) by means of $\Delta 133 \mathrm{p} 53 \alpha$ lentiviral transduction (Fig. 4a). $\Delta 133 \mathrm{p} 53 \alpha$ overexpressing HPECs reproducibly bypassed the normal senescence barrier and continued to proliferate for six additional passages in KGM culture, whereas HPECs transduced with the empty vector stopped proliferating after two additional passages (Fig. 4b, c). A similar result was observed in $\Delta 133 \mathrm{p} 53 \alpha-$ overexpressing HFKs, which continued to proliferate for five additional passages in KGM compared to control cells (Fig. 4d and Supplementary Information Fig. S12). 


\begin{abstract}
(see figure on previous page)
Fig. 3 Knockdown of endogenous $\Delta 133 p 53 a$ inhibits cell proliferation in KGM and CR cultures. Two independent siRNAs ( $\triangle 133$-siR\#1 and $\triangle 133-$-siR\#2) were designed to target sequences present in $\triangle 133 p 53$ a mRNA as $5^{\prime}$-UTRs that are spliced out of full-length p53 mRNA. Transfection was performed in KGM using early-passage HPECS (P3) and HFKs (P4). The control siRNA (Scr-Control) was a scrambled sequence of $\triangle 133$-siR\#1. a Immunoblot analysis of $\triangle 133 p 53 a$ and full-length p53 proteins at 3 days post-transfection. GAPDH was used as a loading control. Normalized densitometric values for expression levels are indicated below each lane relative to Scr-Control cells (defined as 1.0). Representative images of the transfected HFKs are shown in Supplementary Information Fig. S9a, b. b Proliferation of the transfected HPECs and $\mathbf{c}$ HFKs were monitored for 4 days using IncuCyte. Data are mean \pm S.D. from triplicate wells. $\mathbf{d}$ Immunoblot analysis for $\triangle 133 p 53 a$ and full-length p53 proteins at 3 days posttransfection of the HFKs with Scr-Control, $\triangle 133$-siR\#1 and $\triangle 133$-siR\#2 siRNA in conditioned media (CM). These HFKs were initially cultured in CRC for eight passages (HFK_CRC/P8) and then cultured in CM for another three passages (CM/P3) before transfection. GAPDH was used as a loading control. Normalized densitometric values are indicated below each lane. e Proliferation of the transfected HFKs in $\mathbf{d}$ were monitored for 4 days posttransfection using IncuCyte. Data are the mean \pm S.D. from triplicate wells. Representative images of the transfected HFKs are shown in Supplementary Information Fig. S10. f Expression of $\triangle 133 p 53$, full-length p53 and hTERT mRNA in the transfected HFKs in $\mathbf{d}$ were measured by qRTPCR at 3 days post-transfection in conditioned medium (CM). $\beta 2$-microglobulin mRNA was used for normalization. Data are mean \pm S.D. from three independent experiments. ${ }^{*} P<0.05 ;{ }^{*} P<0.01 ;{ }^{* *} P<0.001$. Uncropped blot images are shown in Supplementary Information Figs. S29-30
\end{abstract}

To investigate the effect of $\Delta 133 \mathrm{p} 53 \alpha$ in the rapidly growing cells at early passages, we next overexpressed $\Delta 133 p 53 \alpha$ in both HPEC and HFK cells at passage 2 (P2) and examined their proliferation status both shortterm and long-term (Fig. 4e). In short-term assays, $\triangle 133 p 53 \alpha$-overexpressing HPECs became confluent after 7 days, whereas the control cells were growing slowly and reached only 40-45\% (Supplementary Information Fig. S13a, b). In long-term assays, the empty vector control cells proliferated only $4-5$ population doubling levels while the cells overexpressing $\Delta 133 p 53 \alpha$ continued to grow an additional 15 population doubling levels (ten more passages) before they ceased proliferating and became senescent (Fig. 4f, $g$ and Supplementary Information, Figs. S13c, d and S14). The extension of replicative lifespan by overexpressing $\triangle 133 p 53 \alpha$ was also consistent in two other HPECs and HFKs generated from two different individuals (prostate-2 and foreskin-2) (Supplementary Information, Fig. S15). Therefore, we conclude that $\Delta 133 p 53 \alpha$ overexpression promotes cell proliferation and can extend the replicative lifespan of primary HPECs and HFKs without the use of CR culture.

\section{$\Delta 133 p 53 a$ upregulates hTERT expression and telomerase activity in primary cells}

In light of our current finding that $\Delta 133 \mathrm{p} 53 \alpha$ is highly expressed in CR cells and previous reports of increased hTERT mRNA and telomerase activity in CR cells ${ }^{12,36}$ we asked if there is a link between $\triangle 133 \mathrm{p} 53 \alpha$ and hTERT expression in primary epithelial cells. A 2-5-fold increase in hTERT mRNA expressions (compared to empty vector control cells) were observed in both the HPECs and HFKs overexpressing $\Delta 133 p 53 \alpha$ (Fig. $5 \mathrm{a}$ ). We also observed that overexpression of $\Delta 133 \mathrm{p} 53 \alpha$ had no effect on full-length p53 and E2F1, but reduced p53 targets p21, PUMA, NOXA, and BAX that are associated with cell-cycle arrest, apoptosis and senescence (Supplementary Information
Fig. S16). Interestingly, the $\Delta 133 \mathrm{p} 53 \alpha$-overexpressing epithelial cells also exhibited a 5-15-fold increase in telomerase activity (Fig. 5b). These results demonstrate that $\triangle 133 \mathrm{p} 53 \alpha$ upregulates hTERT expression in primary epithelial cells.

\section{hTERT is required for cell proliferation in $\Delta 133 p 53 a-$ overexpressing cells}

To further establish a link between $\triangle 133 \mathrm{p} 53 \alpha$, hTERT and proliferation in primary cells, siRNA was used to knockdown endogenous hTERT in KGM cultures of $\triangle 133 p 53 \alpha$-overexpressing HFKs and HPECs. As shown (Fig. 6a), siRNA effectively reduced levels of hTERT mRNA by 60 (HFKs) and 80\% (HPECs) compared to non-specific control siRNA. Interestingly, we observed clear inhibition of cell proliferation in both the cell types transfected with hTERT-siRNA, whereas cells transfected with control siRNA continued to proliferate at the same rate as none (no siRNA)-transfected cells (Fig. 6b, c and Supplementary Information Fig. S17a, b). Moreover, knockdown of hTERT expression in the $\Delta 133 \mathrm{p} 53 \alpha$-overexpressing cells showed much stronger and immediate inhibition of cell proliferation when no ROCK inhibitor (Y-27632) was added to the culture medium (Fig. 6d). Altogether, these findings suggest that the induction of hTERT by $\Delta 133 \mathrm{p} 53 \alpha$ is required for continued cell proliferation.

\section{$\Delta 133 p 53 a$ immortalizes primary epithelial cells in cooperation with Rho-associated kinase (ROCK) inhibitor}

It is well documented that the ROCK inhibitor, Y27632, enhances cell survival by inhibiting differentiation and apoptotic pathways ${ }^{15,37,38}$. Furthermore, the combined effects of ROCK inhibitor and increased hTERT expression are sufficient to conditionally immortalize primary epithelial cells ${ }^{12,14,15}$. Since we have shown that hTERT expression and telomerase activity are increased in $\triangle 133 \mathrm{p} 53 \alpha$-overexpressing primary HFKs and HPECs, 


\section{LATE PASSAGE}

a

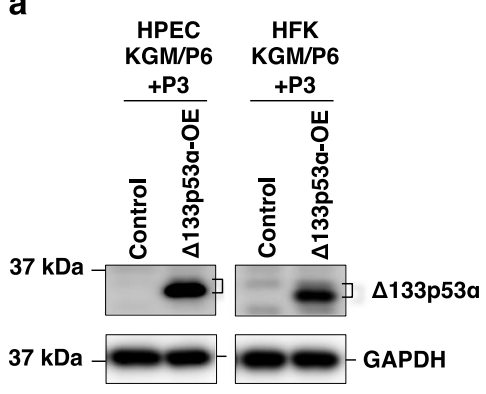

c

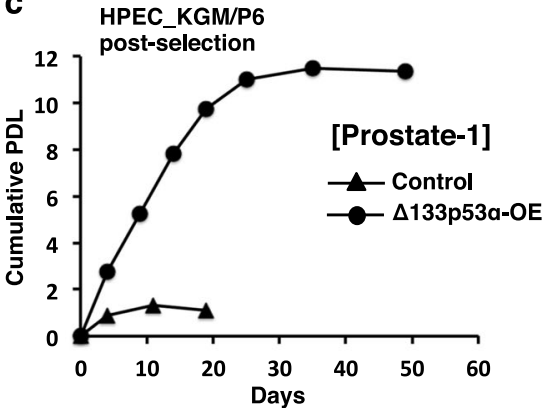

b
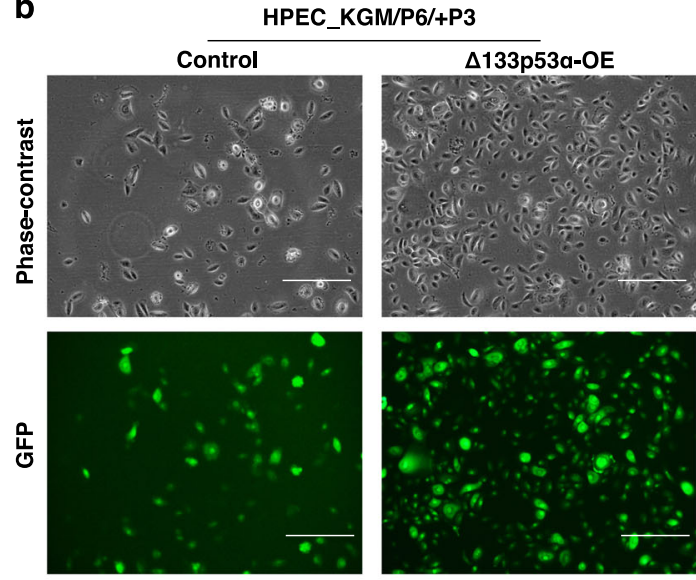

d HFK_KGM/P6

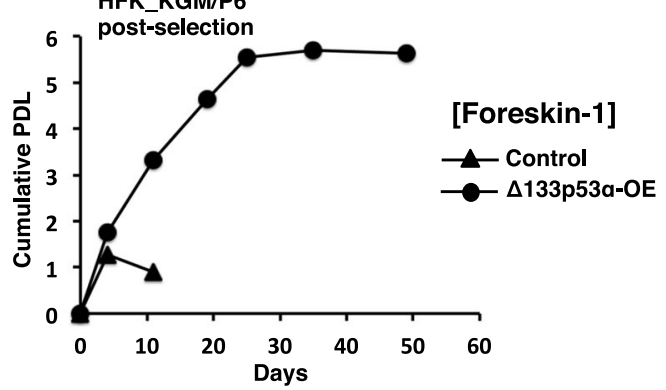

EARLY PASSAGE

e

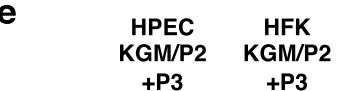

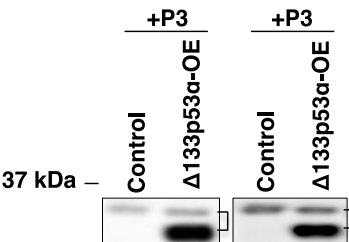

$37 \mathrm{kDa}$
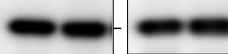

- GAPDH

g

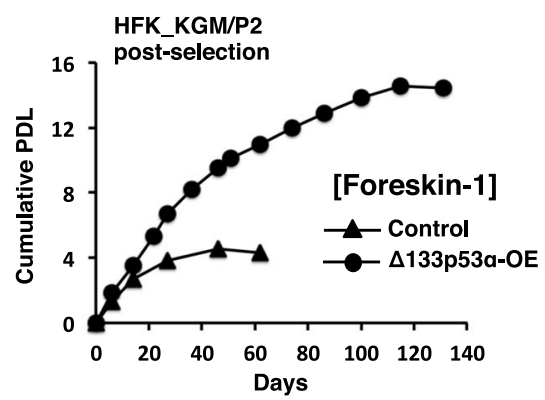

f

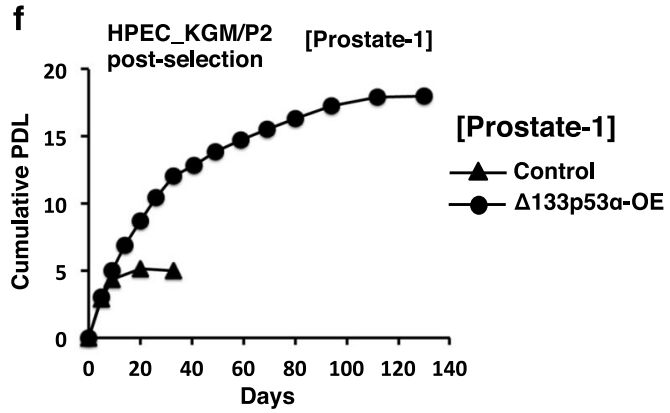

Fig. 4 (See legend on next page.) 
(see figure on previous page)

Fig. 4 Overexpression of $\Delta \mathbf{1 3 3 p 5 3 a}$ extends the replicative lifespan. Late-passage (P6) KGM cultures of HPECs and HFKs were transduced with lentivirus containing an empty GFP-tagged vector (control) or GFP-tagged $\triangle 133 p 53 a$ to induce $\triangle 133 p 53 a$ overexpression ( $\triangle 133 p 53 a-O E)$ and selected with blasticidin for three passages (+P3). a Immunoblots showing $\triangle 133 p 53$ a overexpression (lower band). Slightly slower migrating band represents their endogenous levels. GAPDH was used as a loading control. b Representative images of control and $\triangle 133 p 53 a-O E ~ H P E C s$ three passages after selection (HPEC_KGM/P6/+P3). Upper panel: phase-contrast microscopy. Lower panel: GFP fluorescence microscopy. Scale bars: 400 $\mu \mathrm{m}$. Representative images of the transduced HFKs are shown in Supplementary Information Fig. S12. c, d Cumulative population doubling levels (PDLs) were calculated and plotted to days post-selection of HPECs (from prostate-1) and HFKs (foreskin-1) as indicated. e Early-passage (P2) KGM cultures of HPECs and HFKs were transduced and selected as above. Overexpression of $\triangle 133 p 53 a$ was confirmed by immunoblotting (lower band). Slightly slower migrating band represents their endogenous levels. GAPDH was a loading control. Representative images of the post-selected HPECS and HFKs are shown in Supplementary Information Fig. S13c, d. f, $\mathbf{g}$ The proliferation of all four cell lines was followed, beginning three passages after selection. Cumulative PDLs were plotted vs. time (days). The HPECs and HFKs shown in this figure were generated from prostate-1 and foreskin-1,

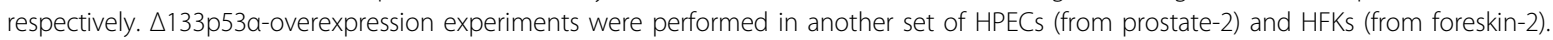
Cumulative PDLs for proliferation assays are shown in Supplementary Information Fig. S15. Uncropped blot images are shown in Supplementary Information Figs. S32-33
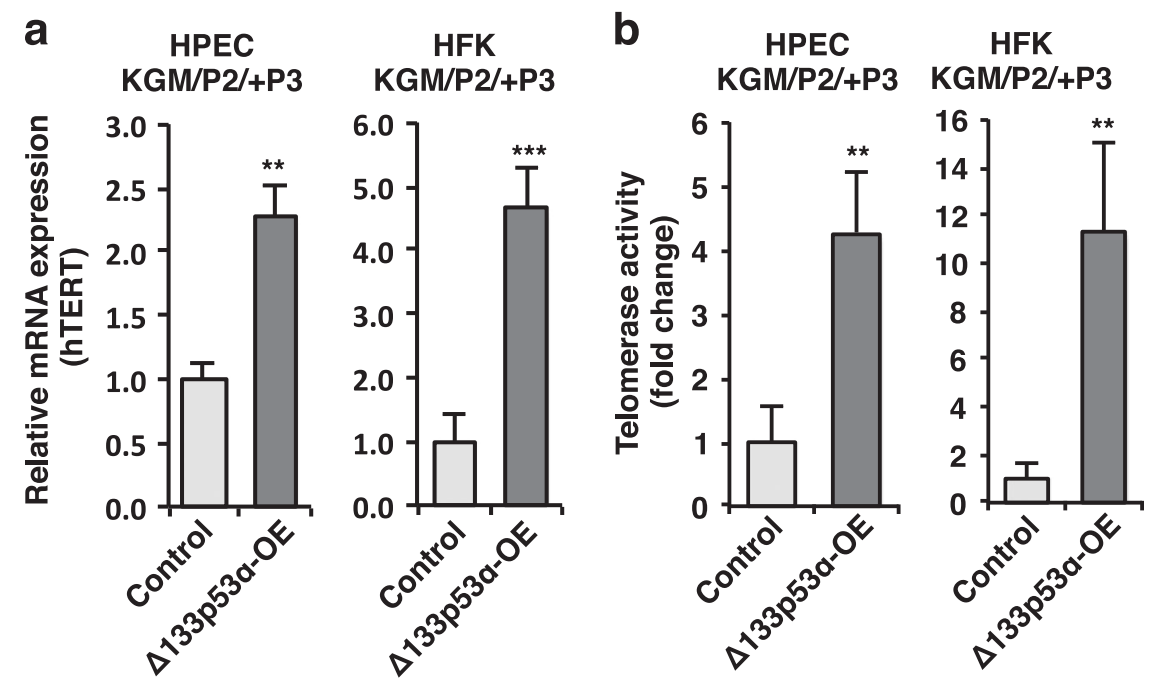

Fig. $5 \Delta 133 p 53 a$ increases hTERT mRNA levels and telomerase activity. a qRT-PCR analysis of hTERT mRNA levels in $\triangle 133 p 53 a-o v e r e x p r e s s i n g$ ( $\triangle 133$ p53a-OE) HFK and HPEC cells three passages after selection in KGM. The empty GFP-tagged vector was used as a control. $\beta 2$-microglobulin mRNA was used for normalization. Data are mean \pm S.D. from three independent experiments. ${ }^{* *} P<0.01 ;{ }^{* * *} P<0.001$. b Telomerase activity was measured in the same $\triangle 133$ p53a-OE HFK and HPEC cells three passages after selection in KGM. The empty GFP-tagged vector was used as a control. Data are expressed as mean \pm S.D. from three independent experiments. ${ }^{*} P<0.01$

we asked if these cells could be immortalized by the addition of Y-27632. Initially, Y-27632 was not added to hTERT-overexpressing HFKs when culturing in KGM. HFKs overexpressing hTERT continued to proliferate indefinitely in presence of Y-27632, whereas the same cells stopped growing after seven passages without Y27632 (Fig. 7a). To investigate if $\Delta 133 p 53 \alpha$ can substitute for hTERT, $\Delta 133 p 53 \alpha$-overexpressing HFKs and HPECs were cultured in KGM in the presence or absence of Y27632. As observed with hTERT overexpression, both HFKs- and HPECs-overexpressing $\Delta 133 \mathrm{p} 53 \alpha$ continued to grow indefinitely in KGM supplemented with Y-27632, whereas the same cells stopped growing after 6-8 passages without Y-27632 (Fig. 7b, c). Taken together, our data indicate that $\Delta 133 \mathrm{p} 53 \alpha$ overexpression and a ROCK inhibitor can immortalize primary epithelial cells and that the effect of $\Delta 133 \mathrm{p} 53 \alpha$ is related to its ability to induce hTERT expression.

\section{Discussion}

In the current study, we show that the expression of both full-length p53 and its natural isoform, $\Delta 133 \mathrm{p} 53 \alpha$, are upregulated in CR primary epithelial cells (HFKs and HPECs). In particular, $\Delta 133 \mathrm{p} 53 \alpha$ levels are closely correlated with proliferation. In non-CR cultures (KGM), early-passage primary cells express high levels of $\Delta 133 p 53 \alpha$, which decrease and eventually disappear as later-passage cells become senescent. Conversely, CR cultures of primary HFKs and HPECs exhibit rapid growth inhibition and loss of $\Delta 133 \mathrm{p} 53 \alpha$ expression when transferred to KGM. These findings are consistent with previous studies that demonstrated increased autophagic 
a
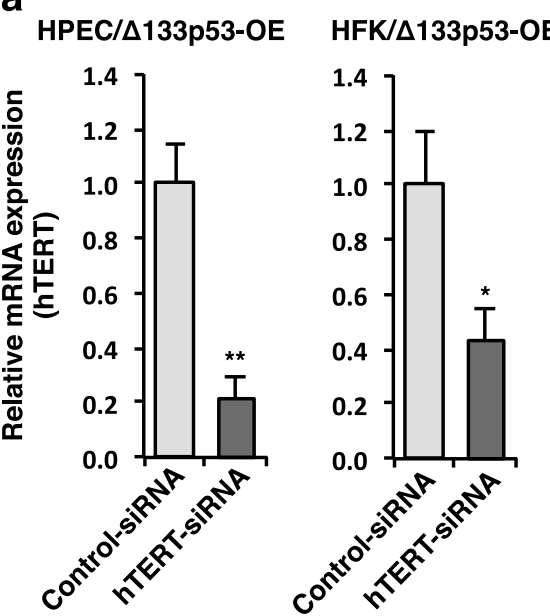

C

HFK/ $133 p 53-O E$

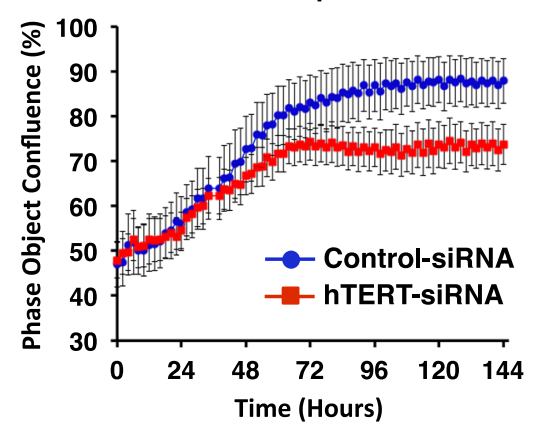

b

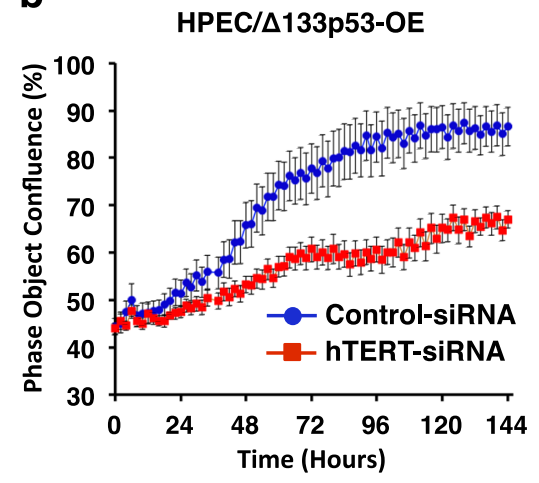

d

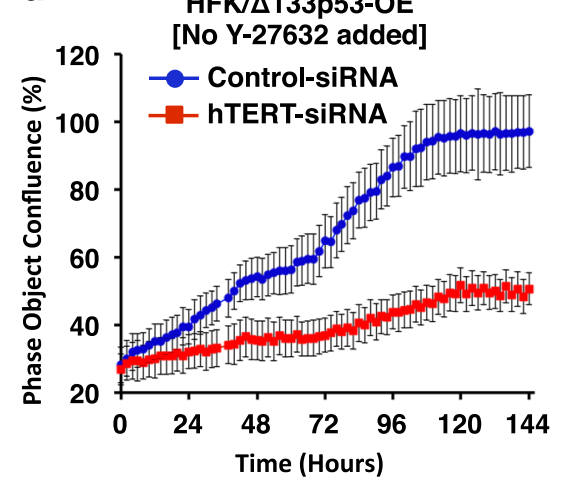

Fig. 6 hTERT is required for cell proliferation in $\mathbf{\Delta 1 3 3 p 5 3 a - o v e r e x p r e s s i n g ~ c e l l s . ~ a ~ K G M ~ c u l t u r e s ~ o f ~} \triangle 133 p 53 a-O v e r e x p r e s s i n g ~(\triangle 133 p 53 a-O E)$ HPECs (at passage 9) and HFKs (at passage 6) were transfected with hTERT-siRNA or control siRNA. hTERT mRNA expressions were measured by qRTPCR. $\beta 2$-microglobulin mRNA was used for normalization. Data are mean \pm S.D. from three independent experiments. ${ }^{*} P<0.05$; ${ }^{* *} P<0.01$.

b Proliferation of $\triangle 133 p 53 a-O E$ HPECs and $\mathbf{c ~ H F K s ~ w e r e ~ m e a s u r e d ~ f o r ~} 6$ days after transfection in IncuCyte. Data are expressed as mean \pm S.D. from triplicate wells. Representative images of HPECs and HFKs transfected with hTERT-siRNA and control siRNA are shown in Supplementary Information Fig. S17. d Proliferation of $\triangle 133 p 53 a-O E$ HFKs were measured in IncuCyte for 6 days after transfection with hTERT-siRNA or control siRNA in the absence of ROCK inhibitor Y-27632. Data are expressed as mean \pm S.D. from triplicate wells

degradation of $\Delta 133 \mathrm{p} 53 \alpha$ in senescent primary human fibroblasts $^{25,39}$. Moreover, we show that $\Delta 133 \mathrm{p} 53 \alpha$ overexpression consistently delays senescence with loss of p53 targets $\mathrm{p} 21$, PUMA, NOXA, and BAX that are implicated in cell-cycle arrest, apoptosis, or senescence (Supplementary Information Figs. S14 and S16) and extends the replicative lifespan of primary HFKs and HPECs, in agreement with the role of $\Delta 133 \mathrm{p} 53 \alpha$ dominant-negative inhibition of full-length p53 at p21 expression to suppress early onset of senescence ${ }^{40}$ and to enhance the generation of induced pluripotent stem cells ${ }^{41}$. The correlation between $\Delta 133 \mathrm{p} 53 \alpha$ expression and proliferation is further supported by the observation that siRNA knockdown of endogenous $\Delta 133 \mathrm{p} 53 \alpha$ under either synthetic serum-free medium (KGM) or CR culture results in immediate growth arrest. As previously reported, siRNA oligos used to knockdown $\Delta 133 \mathrm{p} 53 \mathrm{mRNA}$ also reduce $\Delta 160 \mathrm{p} 53 \alpha$ protein isoform. Expression of $\Delta 133 \mathrm{p} 53 \alpha$ and $\Delta 160 \mathrm{p} 53 \alpha$ protein isoforms from the same $\Delta 133 \mathrm{p} 53 \mathrm{mRNA}$ are cell type specific ${ }^{24}$. Therefore, it remained unclear whether any biological effects were associated with only $\Delta 133 \mathrm{p} 53$ or $\Delta 160 \mathrm{p} 53$ or both. We did not see any detectable $\Delta 160 p 53 \alpha$ protein in western blots using CM1 antibody in the primary epithelial cells when $\Delta 133 \mathrm{p} 53 \alpha$ was either knocked-down (Supplementary Information Figs. S11 and S30) or overexpressed (Supplementary Information Fig. S31). Therefore, the possibility of $\Delta 160 p 53 \alpha$ having any significant role in cell proliferation has been excluded in this study. Altogether, these results suggest that $\Delta 133$ p $53 \alpha$ plays an important role in the CR of primary epithelial cells.

hTERT, a specialized RNA-dependent DNA polymerase, maintains telomere length and plays a critical role in cellular survival and immortalization ${ }^{42,43}$. It is well 


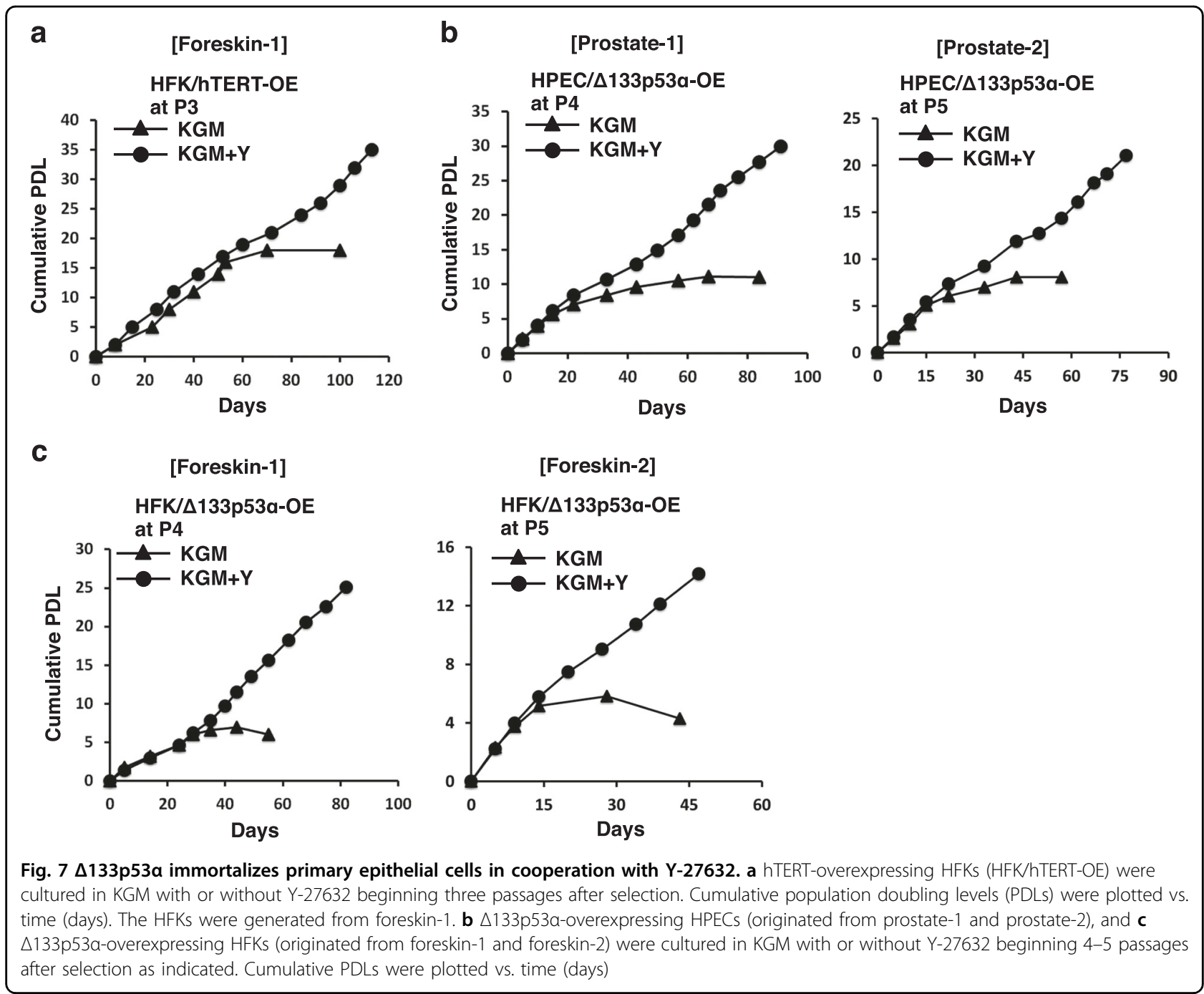

known that wild-type p53 downregulates hTERT expression and that hTERT counteracts apoptosis induced by $\mathrm{p} 53^{44,45}$. However, emerging details of p53mediated cell survival ${ }^{46,47}$ and the regulation of telomere lengthening in cancer cells ${ }^{48}$ raise new questions regarding the interplay of p53 and hTERT. Recently, we showed that $\Delta 133 \mathrm{p} 53 \alpha$ physically interacts with wild-type p53 and likely inhibits p53-mediated apoptosis and senescence in a dominant-negative manner ${ }^{41,49}$ and speculated that increased $\Delta 133 p 53 \alpha$ expression might be important for CR. In the present study, we show that the $\Delta 133 \mathrm{p} 53 \alpha-$ overexpressing primary epithelial cells exhibit increased levels of hTERT mRNA and telomerase activity (Fig. 5a, b), which is consistent with the loss of hTERT expression in the $\Delta 133 p 53 \alpha$-siRNA-knockdown cells (Fig. 3f). In addition, we observed rapid cell death when siRNA was used to knockdown endogenous hTERT in the $\Delta 133 p 53 \alpha$-induced reprogrammed cells (Fig. 6b-d). This hTERT-siRNA-knockdown effect on growth inhibition was much stronger and immediate in absence of ROCK inhibitor (Fig. 6d). These findings show that hTERT expression and telomerase activity are required for longterm passaging or $\mathrm{CR}$ of epithelial cells, and that $\Delta 133 \mathrm{p} 53 \alpha$-mediated upregulation of hTERT contributes to inhibit full-length p53-mediated apoptosis or cellular senescence in vitro $^{50}$ (Supplementary Information Fig. S16).

hTERT is essential for maintaining or elongating telomeres, thus allowing for continued cell replication ${ }^{51}$. However, our previous studies showed that HPV E6induced telomerase activity was dissociated from telomere maintenance during cell immortalization ${ }^{52}$. This is consistent with our findings that $C R$ and $\Delta 133 p 53 \alpha$ overexpression result in long-term cell proliferation despite the erosion and shortening of telomere length. The mechanisms that stabilize these short telomeres and prevent senescence or apoptosis is incompletely understood at this time. What is clear is that CR culture 
conditions and $\Delta 133 \mathrm{p} 53 \alpha$ overexpression both appear to function as inducers of hTERT and that this activity, when combined with the cytoskeletal destabilizing activity of ROCK inhibitor, is critical for the prolonged proliferation of "primary" cell cultures.

\section{Acknowledgements}

This work was supported by the following NIH grants: R33 CA177466 to R.S. R21 CA180524-01 to X.L., Shenzhen Sanming Project (SZSM 201512039) to X.L. and L.Y., and internal support from the Center for Cell Reprogramming at Georgetown University Medical Center. We thank Hang Yuan, Ewa Krawczyk, Seema Argawal, and Anton Wellstein for helpful discussions during the course of this study.

\section{Author details}

${ }^{1}$ Center for Cell Reprograming, Department of Pathology, Georgetown University Medical Center, Georgrtown, WA 20057, USA. ${ }^{2}$ Guizhou Medical University, Guiyang, Guizhou, China. ${ }^{3}$ Laboratory of Human Carcinogenesis, Center for Cancer Research, National Cancer Institute, National Institutes of Health, Bethesda, MD 20892, USA. ${ }^{4}$ Shenzhen Eye Hospital, Shenzhen, Guangdong, China. ${ }^{5}$ Second Xianya Hospital (Adjunct Position), Zhongnan University, Changsha, Huna, China. ${ }^{6}$ Affiliated Cancer Hospital \& Institute (Adjunct Position), Guangzhou Medical University, Guangzhou, Guangdong, China

\section{Conflict of interest}

Georgetown University has been awarded two patents by the United States Patent Office (US9,279,106 and US9,657,272) for conditional reprogramming. This technology has been licensed exclusively to a biotechnology company, Propagenix, for commercialization. Georgetown University and the inventors (X.L., R.S.) receive payments and potential royalties from Propagenix.

\section{Publisher's note}

Springer Nature remains neutral with regard to jurisdictional claims in published maps and institutional affiliations.

Supplementary Information accompanies this paper at (https://doi.org/ 10.1038/s41419-018-0767-7).

Received: 12 February 2018 Revised: 25 May 2018 Accepted: 8 June 2018 Published online: 03 July 2018

\section{References}

1. Collado, M., Blasco, M. A., \& Serrano, M. Cellular senescence in cancer and aging. Cell 130, 223-233 (2007).

2. Harley, C. B., Vaziri, H., Counter, C. M. \& Allsopp, R. C. The telomere hypothesis of cellular aging. Exp. Gerontol. 27, 375-382 (1992).

3. Campisi, J. Cancer, aging and cellular senescence. Vivo 14, 183-188 (2000).

4. Kahn, J., Tofilon, P. J. \& Camphausen, K. Preclinical models in radiation oncology. Radiat. Oncol. 7, 223 (2012).

5. Cunderlikova, B. Issues to be considered when studying cancer in vitro. Crit. Rev. Oncol. Hematol. 85, 95-111 (2013).

6. Van der Haegen, B. A. \& Shay, J. W. Immortalization of human mammary epithelial cells by SV40 large T-antigen involves a two step mechanism. Vitr. Cell. Dev. Biol.: J. Tissue Cult. Assoc. 29a, 180-182 (1993).

7. Liu, X. et al. Cell-restricted immortalization by human papillomavirus correlates with telomerase activation and engagement of the hTERT promoter by Myc. J. Virol. 82, 11568-11576 (2008).

8. Hawley-Nelson, P., Vousden, K. H., Hubbert, N. L., Lowy, D. R. \& Schiller, J. T. HPV16 E6 and E7 proteins cooperate to immortalize human foreskin keratinocytes. EMBO J. 8, 3905-3910 (1989).

9. Roig, A. I. et al. Immortalized epithelial cells derived from human colon biopsies express stem cell markers and differentiate in vitro. Gastroenterology 138, 1012-1021 (2010).
10. Takahashi, K., \& Yamanaka, S. Induction of pluripotent stem cells from mouse embryonic and adult fibroblast cultures by defined factors. Cell 126, 663-676 (2006).

11. Liu, X. et al. Conditional reprogramming and long-term expansion of normal and tumor cells from human biospecimens. Nat. Protoc. 12, 439-451 (2017).

12. Liu, X. et al. ROCK inhibitor and feeder cells induce the conditional reprogramming of epithelial cells. Am. J. Pathol. 180, 599-607 (2012).

13. Yuan, $\mathrm{H}$. et al. Use of reprogrammed cells to identify therapy for respiratory papillomatosis. N. Eng. J. Med. 367, 1220-1227 (2012).

14. Suprynowicz, F. A. et al. Conditionally reprogrammed cells represent a stemlike state of adult epithelial cells. Proc. Natl Acad. Sci. USA 109, 20035-20040 (2012).

15. Chapman, S., Liu, X., Meyers, C., Schlegel, R. \& McBride, A. A. Human keratinocytes are efficiently immortalized by a Rho kinase inhibitor. J. Clin. Invest. 120, 2619-2626 (2010).

16. Oren, M. Decision making byp53: life, death and cancer. Cell Death Differ. 10, 431-442 (2003).

17. Bates, S. \& Vousden, K. H. Mechanisms of p53-mediated apoptosis. Cell. Mol. life Sci.: CMLS 55, 28-37 (1999).

18. Ryan, K. M., Phillips, A. C. \& Vousden, K. H. Regulation and function of the p53 tumor suppressor protein. Curr. Opin. Cell Biol. 13, 332-337 (2001).

19. Chen, J. et al. p53 isoform delta113p53 is a p53 target gene that antagonizes p53 apoptotic activity via BclxL activation in zebrafish. Genes Dev. 23, 278-290 (2009).

20. Bourdon, J. C. et al. p53 isoforms can regulate p53 transcriptional activity. Genes Dev. 19, 2122-2137 (2005).

21. Senturk, S. et al. p53Psi is a transcriptionally inactive p53 isoform able to reprogram cells toward a metastatic-like state. Proc. Natl. Acad. Sci. USA 111 E3287-E3296 (2014)

22. Khoury, M. P. \& Bourdon, J. C. p53 Isoforms: An Intracellular Microprocessor? Genes Cancer 2, 453-465 (2011).

23. Bourdon, J. C. p53 isoforms change p53 paradigm. Mol. Cell. Oncol. 1, e969136 (2014).

24. Marcel, V. et al. Delta160p53 is a novel N-terminal p53 isoform encoded by Delta133p53 transcript.FEBS Lett. 584, 4463-4468 (2010).

25. Fujita, K et al. p53 isoforms Delta133p53 and p53beta are endogenous regulators of replicative cellular senescence. Nat. Cell Biol. 11, 1135-1142 (2009).

26. Mondal, A. M. et al. p53 isoforms regulate aging- and tumor-associated replicative senescence in T Iymphocytes. J. Clin. Invest. 123, 5247-5257 (2013).

27. Turnquist, $\mathrm{C}$. et al. p53 isoforms regulate astrocyte-mediated neuroprotection and neurodegeneration. Cell Death Differ. 23, 1515-1528 (2016)

28. Palechor-Ceron, N. et al. Radiation induces diffusible feeder cell factor(s) that cooperate with ROCK inhibitor to conditionally reprogram and immortalize epithelial cells.Am. J. Pathol. 183, 1862-1870 (2013).

29. Schlegel, R., Phelps, W. C., Zhang, Y. L. \& Barbosa, M. Quantitative keratinocyte assay detects two biological activities of human papillomavirus DNA and identifies viral types associated with cervical carcinoma. EMBO J. 7, 3181-3187 (1988).

30. Khoury, M. P. \& Bourdon, J. C. The isoforms of the p53 protein. Cold Spring Harb. Perspect. Biol. 2, a000927 (2010).

31. Kim, N. W. \& Wu, F. Advances in quantification and characterization of telomerase activity by the telomeric repeat amplification protocol (TRAP). Nucl. Acids Res. 25, 2595-2597 (1997).

32. Liu, $X$. et al. The E6AP ubiquitin ligase is required for transactivation of the hTERT promoter by the human papillomavirus E6 oncoprotein. J. Biol. Chem. 280, 10807-10816 (2005).

33. Veldman, T., Horikawa, I., Barrett, J. C., \& Schlegel, R. Transcriptional activation of the telomerase hTERT gene by human papillomavirus type 16 E6 oncoprotein. J. Virol. 75, 4467-4472 (2001)

34. Fu, B., Quintero, J. \& Baker, C. C. Keratinocyte growth conditions modulate telomerase expression, senescence, and immortalization by human papillomavirus type 16 E6 and E7 oncogenes. Cancer Res. 63, 7815-7824 (2003).

35. Rufini, A., Tucci, P., Celardo, I. \& Melino, G. Senescence and aging: the critical roles of p53. Oncogene 32, 5129-5143 (2013).

36. Liu, X., Roberts, J., Dakic, A., Zhang, Y., \& Schlegel, R. HPV E7 contributes to the telomerase activity of immortalized and tumorigenic cells and augments E6induced hTERT promoter function.Virology 375, 611-623 (2008). 
37. Chapman, S., McDermott, D. H., Shen, K., Jang, M. K. \& McBride, A. A. The effect of Rho kinase inhibition on long-term keratinocyte proliferation is rapid and conditional. Stem Cell Res. Ther. 5, 60 (2014).

38. Shi, J. \& Wei, L. Rho kinase in the regulation of cell death and survival. Arch Immunol. Ther. Exp. (Warsz.) 55, 61-75 (2007).

39. Horikawa, I. et al. Autophagic degradation of the inhibitory p53 isoform Delta133p53alpha as a regulatory mechanism for p53-mediated senescence. Nat. Commun. 5, 4706 (2014).

40. von Muhlinen, $\mathrm{N}$. et al. p53 isoforms regulate premature aging in human cells. Oncogene 37, 2379-2393 (2018).

41. Horikawa, I. et al. Delta133p53 represses p53-inducible senescence genes and enhances the generation of human induced pluripotent stem cells. Cell Death Differ. 24, 1017-1028 (2017).

42. Greider, C. W. \& Blackburn, E. H. Telomeres, telomerase and cancer. Sci. Am. 274, 92-97 (1996)

43. Lee, H. W. et al. Essential role of mouse telomerase in highly proliferative organs. Nature 392, 569-574 (1998)

44. Rahman, R., Latonen, L. \& Wiman, K. G. hTERT antagonizes p53-induced apoptosis independently of telomerase activity. Oncogene 24, 1320-1327 (2005).
45. $\mathrm{Xu}, \mathrm{D}$. et al. Downregulation of telomerase reverse transcriptase mRNA expression by wild type p53 in human tumor cells. Oncogene 19, 5123-5133 (2000).

46. Singh, B. et al. p53 regulates cell survival by inhibiting PIK3CA in squamous cell carcinomas. Genes Dev. 16, 984-993 (2002).

47. Sen, N., Satija, Y. K. \& Das, S. PGC-1alpha, a key modulator of p53, promotes cell survival upon metabolic stress. Mol. Cell 44, 621-634 (2011).

48. Cesare, A. J. \& Reddel, R. R. Alternative lengthening of telomeres: models, mechanisms and implications. Nat. Rev. Genet. 11, 319-330 (2010).

49. Horikawa, I., \& Harris, C. C. Delta133p53: A p53 isoform enriched in human pluripotent stem cells. Cell Cycle 16, 1631-1632 (2017).

50. Miller, J. et al. HPV16 E7 protein and hTERT proteins defective for telomere maintenance cooperate to immortalize human keratinocytes. PLoS Pathog. 9 e1003284 (2013).

51. Greider, C. W. Telomere length regulation. Annu. Rev. Biochem. 65, 337-365 (1996).

52. Stoppler, H., Hartmann, D. P., Sherman, L. \& Schlegel, R. The human papillomavirus type $16 \mathrm{E} 6$ and E7 oncoproteins dissociate cellular telomerase activity from the maintenance of telomere length. J. Biol. Chem. 272, 13332-13337 (1997). 